Scientific Letter

\title{
Human T-cell Leukemia Virus Type I Associated with an Increased Risk of Primary Malignant Neoplasm
}

Keywords: Human T-cell leukemia virus type I (HTLV-I), Adult T-cell lymphoma (ATL), Primary malignant neoplasm, Regulatory T-cell (Treg).

Published: April 20, 2018

Received: January 30, 2018

Accepted: March 21, 2018

Citation: Nakaya A., Fujita S., Satake A., Nakanishi T., Azuma Y., Tsubokura Y., Konishi A., Hotta M., Yoshimura H., Ishii K., Ito T., Nomura S. Human T-cell leukemia virus type I associated with an increased risk of primary malignant neoplasm. Mediterr J Hematol Infect Dis 2018, 10(1): e2018024, DOI: http://dx.doi.org/10.4084/MJHID.2018.024

This is an Open Access article distributed under the terms of the Creative Commons Attribution License (https://creativecommons.org/licenses/by-nc/4.0), which permits unrestricted use, distribution, and reproduction in any medium, provided the original work is properly cited.

The correlation between human T-cell leukemia virus type I (HTLV-I) infection and malignant neoplasms other than adult T-cell lymphoma (ATL) remains unknown. However, some previous papers have reported the frequency of primary malignant tumors occurring with HTLV-I infection $^{1,2,3}$, and it seems likely that HTLV-I infection may contribute to the development of primary malignant neoplasms other than ATL. Thus, we analyzed the frequency of primary malignant neoplasms other than ATL in HTLV-Iseropositive patients.

From January 2006 to December 2016, 203 patients were diagnosed as HTLV-I-seropositive at Kansai Medical University Hospital. Serological tests were performed to identify patients with HTLV-I infection. The presence of serum antibody against HTLV-I was determined by western blot analysis, and the clonal integration of provirus DNA was confirmed by southern blot analysis. Subtypes of ATL were defined based on the presence of abnormal lymphocytes, serum lactate dehydrogenase, and calcium, using the criteria described by Shimoyama et al. ${ }^{4}$

The study included a total of 203 HTLV-Iseropositive patients with a median age of 62 (range: 19-86) years old, and $45 \%$ of these subjects were male. Of this population, $43 \%$ were diagnosed as HTLV-I carriers, and $57 \%$ were identified as having ATL. The distribution of ATL subtypes was: $21 \%$ smoldering type, $3 \%$ chronic type, $16 \%$ acute type, and $17 \%$ lymphoma type (Table 1). Among the 203 HTLV-I-seropositive patients, 32 developed a primary malignant neoplasm. Their median age was 64 (range: $41-$ 84 ) years old, $63 \%$ of them were male, and $69 \%$ of them were HTLV-I carriers. This group had the following distribution of ATL subtypes: $31 \%$ smoldering type, $0 \%$ chronic type, $3 \%$ acute type, and 3\% lymphoma type (Table 1). Additionally, $54 \%$ of them had a hematological malignancy other than ATL, and $46 \%$ had a solid tumor. The most frequent type of hematological malignancy in this group was T-cell lymphoma (23\%) (17\% anaplastic large cell lymphoma (ALCL); 3\% peripheral T-cell lymphoma, not otherwise specified (PTCL, NOS); and 3\% natural killer (NK)/T-cell lymphoma), followed B-cell lymphoma $(16 \%)$ (all diffuse large B-cell lymphoma (DLBCL)), myeloproliferative neoplasms (MPN) (9\%), and myelodysplastic

Table 1. Patients' characteristics.

\begin{tabular}{|l|c|c|}
\hline & All patients & $\begin{array}{c}\text { Patients with primary } \\
\text { malignant neoplasm }\end{array}$ \\
\hline No. of patients (n) & 203 & 32 \\
\hline Median age, range (y/o) & $62(19-86)$ & $64(41-84)$ \\
\hline Male sex (\%) & 45 & 63 \\
\hline Carrier (\%) & 43 & 69 \\
\hline Subtype of ATL & & \\
\hline Smoldering (\%) & 22 & 31 \\
\hline Chronic (\%) & 3 & 0 \\
\hline Acute (\%) & 16 & 3 \\
\hline Lymphoma (\%) & 17 & 3 \\
\hline
\end{tabular}

ATL: adult T-cell lymphoma. 
Table 2. Frequency of primary malignant neoplasm.

\begin{tabular}{|l|c|c|c|}
\hline Hematological malignancy & $\%$ & Solid tumor & $\%$ \\
\hline T cell lymphoma & 23 & lung & 16 \\
\hline ALCL & $(17)$ & colon & 9 \\
\hline PTCL, NOS & $(3)$ & prostate & 6 \\
\hline NK/T & $(3)$ & renal & 6 \\
\hline B cell lymphoma & 16 & cervical & 2 \\
\hline DLBCL & $(16)$ & breast & 2 \\
\hline MPN & 9 & liver & 2 \\
\hline MDS & 6 & pancreas & 2 \\
\hline & & oral & 2 \\
\hline
\end{tabular}

ALCL: anaplastic large cell lymphoma. PTCL, NOS: peripheral Tcell lymphoma, not otherwise specified. NK: natural killer. DLBCL: diffuse large B-cell lymphoma. MPN: myeloproliferative neoplasms. MDS: myelodysplastic syndromes

syndromes (MDS) (6\%). Patients with MDS were either a carrier or smoldering type of ATL; thus, they have no history of chemotherapies.

The most frequent primary extra-hematological tumor locations were the lung $(15 \%)$, followed by the colon $(9 \%)$, prostate $(6 \%)$, kidney $(6 \%)$, cervix $(2 \%)$, breast $(2 \%)$, liver $(2 \%)$, pancreas $(2 \%)$, and oral cavity (2\%) (Table 2). Three cases were overlapping more than two malignancies; colon and cervix, colon and renal, $\mathrm{T}$ cell lymphoma and breast. They were two carriers and one smoldering type. The median overall survival of patients with acute type ATL was 9.6 months, and that of lymphoma type ATL was 7.6 months, whereas, those of carrier, smoldering type, and chronic type were not achieved.

Some studies have reported a positive correlation between HTLV-I infection and malignancies other than ATL. Asou et al. signaled that the prevalence of HTLV-I among 394 patients with malignant neoplasm was higher than that among healthy individuals in Kumamoto prefecture in southwestern Japan $(15.48 \%$ vs. $2.98 \%)^{1}$. In that study, the most frequent neoplasm site was the lung ( $\mathrm{n}=82$ ), followed the lymphatics $(n=48)$, stomach $(n=47)$, and liver $(n=33)$. Notably, their finding that the lung was the most common site for solid tumors is consistent with the results of our study. Additionally, the frequency of malignant lymphoma reported by the Asou et al. ${ }^{1}$ study is also compatible with our finding. The high incidence of hepatocellular carcinoma appears to be regionally specific; the prevalence of hepatitis virus infection is higher in western Japan.
Regarding lymphoma, Suefuji et al. reported that B-cell lymphoma patients who were positive for HTLV-I had a worse prognosis than HTLV-Inegative patients (5-year overall survival: $49 \%$ vs. $78 \%, p=0.007) .{ }^{5}$ Furthermore, a study by Brady et al. described a positive relationship between HTLV-I infection and Epstein-Barr virus (EBV) infection. In their study, 3 of 7 HTLV-I carriers developed de novo DLBCL, and these patients were also positive for EBV. ${ }^{6}$ Although not all cases of B-cell lymphoma in HTLV-I carriers involve patients who are also positive for EBV infection, it is possible that when host immunity is suppressed by HTLV-I, EBV may become activated, subsequently leading to the development of B-cell malignant lymphoma. In our institute, we do not routinely examine EBV because it is not covered by insurance. Thus, it is not clear whether our cases are positive for EBV or not.

The prevalence of $\mathrm{T}$-cell lymphoma in our study was high, but this may be the result of inaccurate diagnoses. Morphologically, ATL is challenging to distinguish from PTCL-NOS in pathological tissue unless the monoclonal proliferation of HTLV-I provirus can be proven. Although flow cytometry to detect $\mathrm{CC}$ chemokine receptor 4 (CCR4) often helps to distinguish between these diagnoses, there are some cases in which the flow cytometry results are inconclusive. Furthermore, the confirmation of provirus proliferation cannot be performed without a block of residual tissue, and this procedure is not covered by medical insurance. Therefore, it is presumed that there might be some cases in which provirus proliferation could not be confirmed, leading to these cases being diagnosed clinically as PTCL-NOS.

This study has some limitations, including its retrospective design, a small number of patients and a single facility. Despite a small number of patients, our results revealed that neoplasm prevalence rate with HTLV-I positive is significantly high (about 15\%), compared to total cancer prevalence rate to the population in Osaka (about $0.6 \%)^{7}$

The mechanism responsible for the high prevalence of primary malignant neoplasm associated with HTLV-I infection is currently unknown. We hypothesize that because the chronic HTLV-I infection is associated with host immunosuppression, this condition leads to an increased risk of developing other malignancies. 
There are several reports supporting this speculation. Kannagi et al. revealed that the cytotoxic T-cell response was reduced in HTLV-Iinfected patients. ${ }^{8}$ Additionally, Ogura et al. reported that NK cells were suppressed in ATL. ${ }^{9}$ Notably, regulatory T-cells (Tregs) commonly contribute to suppressing immune responses against tumors, and ATL is described as the malignant proliferation of CD4- and CD25positive cells such that Tregs become tumor cells. ${ }^{10,11}$ Thus, the primary mechanism for the link between HTLV-I infection and malignancy might be host immunosuppression, caused by Tregs becoming tumorigenic, allowing the development of a malignant clone. Further studies are needed to establish what triggers the onset and subsequent development of ATL or other malignancies in HTLV-I-seropositive patients.

In conclusion, our results suggest that HTLV-I infection is often associated with the development of other malignant neoplasms. Therefore, HTLVI-positive patients, including HTLV-I carriers, should be made aware of their increased risk for the onset of a malignant neoplasm and undergo increased surveillance. Further investigations are required to elucidate how HTLV-I affects antitumor immunity.

Acknowledgments. The authors would like to thank Dr. Utsunomiya (Imamura General Hospital, Kagoshima, Japan) for giving us great advice regarding this work.

Aya Nakaya, Shinya Fujita, Atsushi Satake, Takahisa Nakanishi, Yoshiko Azuma, Yukie Tsubokura, Akiko Konishi, Masaaki Hotta, Hideaki Yoshimura, Kazuyoshi Ishii, Tomoki Ito and Shosaku Nomura.

First Department of Internal Medicine, Kansai Medical University

Competing interests: The authors have declared that no competing interests exist.

Correspondence to: Aya Nakaya. First Department of Internal Medicine, Kansai Medical University, 2-5-1, Shin-machi, Hirakata, Osaka 573-1010, JAPAN. Tel: +81-72-804-2503. E-mail: nakaya1016@yahoo.co.jp

\section{References:}

1. Asou N, Kumagai T, Uekihara S, Ishii M, Sato M, Sakai K, Nishimura H, Yamaguchi K, Takatsuki K. HTLV-I seroprevalence in patients with malignancy. Cancer. 1986;58(4):903-907. https://doi.org/10.1002/10970142(19860815)58:4<903::AID- CNCR2820580417>3.0.CO;2-J

2. Imamura N, Inada T, Tagaya Y, Yodoi J, Kuramoto A. Socinski MA, Bondarenko I, Karaseva NA, et al. Association between ATL and nonhematopoietic neoplasms. Hematol Oncol. 1993;11(3):127-137. https://doi.org/10.1002/hon.2900110303 PMid:8112727

3. Kozuru M, Uike N, Muta K, Goto T, Suehiro Y, Nagano M. High occurrence of primary malignant neoplasms in patients with adult $\mathrm{T}$ cell leukemia/lymphoma, their siblings, and their mothers. Cancer. 1996;78(5):1119-1124.

https://doi.org/10.1002/(SICI)1097- 0142(19960901)78:5<1119::AIDCNCR24>3.0.CO;2-4

4. Shimoyama M. Diagnostic criteria and classification of clinical subtypes of adult T-cell leukaemia-lymphoma. A report from the Lymphoma Study Group (1984-87). Br J Haematol. 1991; 79(3):428437. https://doi.org/10.1111/j.1365-2141.1991.tb08051.x PMid: 1751370

5. Suefuji H, Ohshima K, Hayabuchi N, Nakamura K, Kikuchi M. HTLV1 carriers with B-cell lymphoma of localized stage head and neck: prognosis, clinical and immunopathological features. Br J Haematol. 2003; 123(4):606-612.

https://doi.org/10.1046/j.1365- 2141.2003.04653.x PMid:14616963

6. Beltran BE, Qui-ones P, Morales D, Revilla JC, Alva JC, Castillo JJ.
Diffuse large B-cell lymphoma in human T-lymphotropic virus type 1 carriers. Leuk Res Treatment. 2012; 2012:262363. https://doi.org/10.1155/2012/262363

7. http://www.mc.pref.osaka.jp/ocr/en/index.html [accessed Jan 24, 2018]

8. Kannagi M, Matsushita S, Shida H, Harada S. Cytotoxic T cell response and expression of the target antigen in HTLV-I infection. Leukemia. 1994; 8 Suppl 1:S54-59. PMid:8152305

9. Ogura M, Ishida T, Tsukasaki K, Takahashi T, Utsunomiya A. Effects of first-line chemotherapy on natural killer cells in adult T-cell leukemia-lymphoma and peripheral T-cell lymphoma. Cancer Chemother Pharmacol. 2016; 78(1):199- 207.

https://doi.org/10.1007/s00280-016-3070-2 PMid:27289375 PMCid:PMC4921106

10. Karube K, Ohshima K, Tsuchiya T, Yamaguchi T, Kawano R, Suzumiya J, Utsunomiya A, Harada M, Kikuchi M. Expression of FoxP3, a key molecule in CD4CD25 regulatory $\mathrm{T}$ cells, in adult T-cell leukaemia/lymphoma cells. $\mathrm{Br} \mathrm{J}$ Haematol. 2004; 126(1):81-84. https://doi.org/10.1111/j.1365-2141.2004.04999.x PMid:15198736

11. Matsubara Y, Hori T, Morita R, Sakaguchi S, Uchiyama T. Phenotypic and functional relationship between adult $\mathrm{T}$-cell leukemia cells and regulatory T cells. Leukemia. 2005; 19(3):482-483. https://doi.org/10.1038/sj.leu.2403628 PMid:15674359 